\title{
Management of Chronic Facial Pain
}

\author{
Christopher G. Williams, M.D., ${ }^{1}$ A. Lee Dellon, M.D., Ph.D., ${ }^{1,2}$ \\ and Gedge D. Rosson, M.D. ${ }^{1}$
}

\begin{abstract}
Pain persisting for at least 6 months is defined as chronic. Chronic facial pain conditions often take on lives of their own deleteriously changing the lives of the sufferer. Although much is known about facial pain, it is clear that those physicians who treat these conditions should continue elucidating the mechanisms and defining successful treatment strategies for these life-changing conditions. This article will review many of the classic causes of chronic facial pain due to the trigeminal nerve and its branches that are amenable to surgical therapies. Testing of facial sensibility is described and its utility introduced. We will also introduce some of the current hypotheses of atypical facial pain and headaches secondary to chronic nerve compressions and will suggest possible treatment strategies.
\end{abstract}

KEYWORDS: Facial pain, trauma, neuroma, trigeminal nerve

Facial pain is usually immediately obvious to a person and usually immediately disruptive of whatever activity that person is doing. The acute pain may have its origin in an accident, such as a motor vehicle crash with the head hitting the dashboard or airbag, or the acute pain may be iatrogenic, perhaps resulting from excision of a tumor or the consequence of aesthetic surgery. The tissue damage that results from the injury releases chemical mediators that affect the nerves in that tissue, and the nerves themselves may have been injured directly. The small myelinated and nonmyelinated sensory nerve fibers and large myelinated sensory nerve fibers together, but at different velocities, send a pattern of neural impulses to the dorsal column of the spinal cord. From that dorsal root entry zone, the messages are modulated and transmitted up the spinal cord to the midbrain and then to the post-central gyrus, the sensory cortex in the parietal lobe. This pattern of neural impulses is experienced as pain. Clearly, any perception of pain must be, by definition, related to a neural input.

As a reflex to these sensory inputs, motor inputs are initiated. The most immediate one is the "flight or fight" sympathetic response described by Cannon in
1929. Nerves adjacent to the injured territory change their response to chemicals in the environment. Some dorsal root ganglion cells will die due to the peripheral nerve injury. Some interneurons in the dorsal root ganglion will change their firing response for a period of time. And then, if the pain stimulus diminishes in the periphery, the cortical perception of pain diminishes.

However, if the pain stimulus persists, the continuing input of impulses into the spinal cord will contribute to changes throughout the central nervous system to create the condition of chronic pain. Pain persisting for more than 6 months is, by definition, chronic pain. The normal response to a noxious stimulus, pain, will become a pathologic response, and the pain will become a neuropathic response. Part of that neuropathic response is loss of inhibition in the central nervous system, so that stimuli that before injury would not be painful now become painful, causing hypersensitivity and allodynia. Chronic facial pain, as with any other chronic pain, will change a person's life ${ }^{1,2}$ (Fig. 1):

Certainly it is true that when a pain is intense and long-continued, it may dominate the sensorium. It
${ }^{1}$ Division of Plastic Surgery and ${ }^{2}$ Department of Neurosurgery, Johns Hopkins University, Baltimore, Maryland.

Address for correspondence and reprint requests: Gedge D. Rosson, M.D., 601 North Caroline Street, Suite 8161, Baltimore, MD 21287 (e-mail: gedge@jhmi.edu).
Craniomaxillofac Trauma Reconstruction 2009;2:67-76. Copyright (C) 2009 by Thieme Medical Publishers, Inc., 333 Seventh Avenue, New York, NY 10001, USA. Tel: +1(212) 584-4662. Published online: March 5, 2009.

DOI 10.1055/s-0029-1202593. ISSN 1943-3875. 


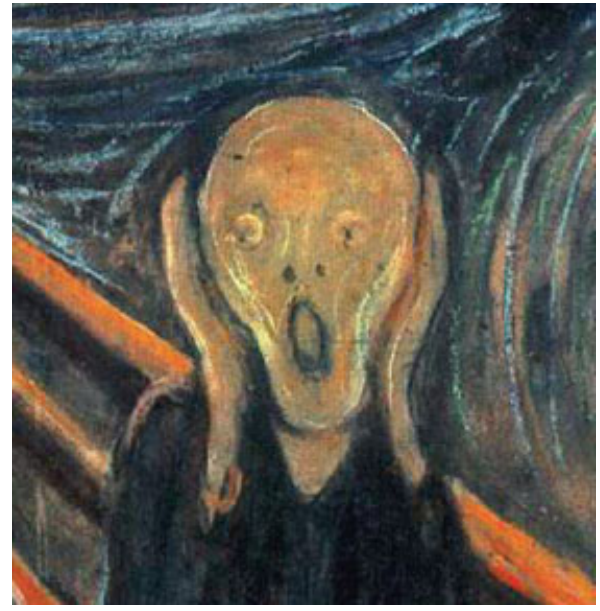

Figure 1 Facial pain can affect the entire person. This excerpt from the painting The Scream, by the Norwegian symbolist painter Edvard Munch, depicts a face in pain. The original was painted in 1893, as oil tempera on cardboard.

interferes with thought processes, it disturbs sleep, impairs appetite, undermines morale, and may disorganize the function of every part of the body. ${ }^{3}$

\section{W.K. Livingston, M.D., 1942}

I am quite certain that most physicians have seen cases in which the constant, persistent, and increasing pains of trigeminal neuralgia, causalgia, and cancer have completely exhausted the patient,... causing a haggard, careworn and prematurely old appearance.... My psychiatrist colleagues and I have seen many patients who manifested psychoneurosis, which I believed was the effect and not the cause of prolonged pain. ${ }^{4}$

$$
\text { J.J. Bonica, M.D., } 1953
$$

It is the purpose of this review to discus the diagnosis and treatment of chronic facial pain. It will become clear that whereas we now have a better understanding of the etiology and mechanisms of chronic facial pain, we have much to discover about its treatment. This review will focus upon chronic facial pain due to lesions of the trigeminal nerve and emphasize the role of neurosensory testing in establishing the diagnosis and treatment plan. In addition to direct nerve injury, chronic compression of the trigeminal nerve will be considered as a source of facial pain, especially with regard to headache.

\section{INTRACRANIAL COMPRESSION OF THE TRIGEMINAL NERVE}

Facial pain that comes on suddenly, is lancinating, and is in the distribution of a branch of the trigeminal nerve is a classic form of chronic facial pain termed trigeminal neuralgia, or tic douloureux. This facial pain problem has been described as "among the most severe pain that mankind suffers ${ }^{5} . . . "$ and is a classic in neurology and neurosurgery. The treatment of tic douloureux has a history of many forms of destructive, intracranial and extracranial ablative approaches to branches of the trigeminal nerve and complete or partial destruction of the trigeminal nucleus. Various medical treatments for this problem, such as use of carbamazepine, have been reported, but these drugs are often poorly tolerated.

However, it is now clear that the majority of patients with this problem have as the etiology chronic vascular compression of the trigeminal nerve root at the base of the skull. When this concept was promulgated in 1967 by P.J. Jannetta, a neurosurgeon at the University of Pittsburgh, it was highly controversial. ${ }^{6}$ His autobiography, ${ }^{7}$ Working in a Very Small Space, describes his tribulations as he persevered to document his concept and his treatment outcome amidst a skeptical medical community. The summary of his 1980 report is instructive $^{8}$ :

As we age, our arteries elongate and our brains "sag." As a consequence of these processes, redundant arterial loops and bridging or intrinsic hindbrain veins may cause cross-compression of cranial nerve root entry zones in the cerebellopontine angle. This pulsatile compression can be seen to produce hyperactive dysfunction of the cranial nerve. Symptoms of trigeminal or glossopharyngeal neuralgia (somatic sensory), hemifacial spasm (somatic motor), tinnitus and vertigo (special sensory) and some cases of "essential" hypertension are caused by these vessels compressing cranial nerves $V$, IX-X, VII, VIII, and left X and medulla oblongata. Using microsurgical techniques, the symptoms may be relieved by vascular decompression, findings and results in 695 patients are briefly reviewed and correlated. A chronic primate model of "essential" hypertension is briefly described.

Posterior fossa microvascular decompression is the treatment of choice for the chronic facial pain related to the trigeminal nerve root compression. The classic term trigeminal neuralgia should be reserved for this clinical entity. The surgical approach was to move the superior cerebellar artery away from the nerve root, maintaining the artery in its new position with a suture. In a recent well-documented series of carefully defined patients, pain relief occurred in $91 \%$ of 362 patients at 1 year. The overall series mean follow-up was 7.2 years. At 15 years, facial pain was still relieved in $73 \%$ of the patients. ${ }^{9}$ In 1996, Jannetta and colleagues published a long-term follow-up study of 1185 patients. They showed a recurrence rate of only $2 \%$ at 5 years and less 
than $1 \%$ at 10 years. Complication rates that required treatment were noted as $1 \%$ for severe facial numbness and less than $0.3 \%$ for dysesthesia. ${ }^{10}$

\section{EXTRACRANIAL TRIGIMENAL NERVE CHRONIC PAIN ETIOLOGIES}

Once the trigeminal nerve leaves the posterior fossa to transverse the cranium and enter the facial skeleton, it undergoes a metamorphosis; while still called a cranial nerve, the trigeminal nerve becomes ensheathed with Schwann cells and will function as a peripheral nerve. This means it will regenerate if injured. This means it can form a painful neuroma if regeneration occurs in a scar milieu. A list of extracranial trigeminal etiologies for chronic pain is given in Table 1.

\section{Nerve Division}

There is a fundamental difference in the approach to a peripheral nerve that is divided, one that is compressed, and one that has formed a painful neuroma. ${ }^{11}$ The divided nerve should be repaired if possible. If a divided nerve is not repaired, then there will be an area of decreased sensation, which will usually decrease in time due to collateral sprouting from adjacent normal nerves. ${ }^{12}$ Collateral sprouting can cause mild acute pain or paresthesias, but rarely causes chronic facial pain. If the divided nerve remains without a repair, it will then sprout axons, attempting to reinnervate their previous distal target. These sprouts may become embedded in scar. In this situation, chronic pain from a neuroma can result. Even if repaired, neural regeneration can be painful in and of itself and result in a chronically painful neuroma at the repair site.

Currently, the best strategy for the injured nerve is to resect an amount of damaged nerve from each end based on the known method of injury; that is, $2 \mathrm{~mm}$ if injured by a sharp knife, proportionately more if cut by glass or jagged material. ${ }^{13,14}$ After resection, there will be a nerve gap that usually cannot be closed using 8-0 nylon without resulting in a repair under tension. Repairs done under tension will fail. Reconstruction of

\section{Table 1 Extracranial Trigeminal Nerve Etiologies for Chronic Facial Pain}

\begin{tabular}{l} 
Nerve injury \\
latrogenic (face lift) \\
Posttraumatic (laceration) \\
Tumor excision \\
Temporomandibular joint \\
Nerve compression \\
Posttraumatic (facial fracture) \\
Muscle "spasm" (migraine) \\
latrogenic (malar augmentation) \\
\hline
\end{tabular}

the defect with a bioabsorbable nerve conduit has been proved in a level I study to give statistically significantly better recovery of a sensory nerve than that of a primary repair or an autogenous nerve graft. ${ }^{15}$ Among cranial nerves, this type of reconstruction using the Neurotube (Synovis Micro Companies Alliance, Birmingham, AL) has been proved successful with the inferior alveolar nerve $\left(\mathrm{V}_{3}\right),{ }^{16}$ the spinal accessory nerve $(\mathrm{XI}),{ }^{17}$ and the facial nerve (VII). ${ }^{18}$

\section{Neuroma}

If the patient with chronic facial pain can point to a trigger point that sets off the pain, and if the area of pain corresponds with a known anatomic distribution of a branch of the trigeminal nerve, then it is likely that a neuroma is present. This implies that the nerve has been damaged. The potential types of damage are iatrogenic, due either to elective or emergency surgery, or posttraumatic secondary to the original accident, like a dashboard hitting the face. The types of surgery most likely to injure the nerve are cosmetic surgery, tumor ablation, or correction of facial fracture. Diagnosis must be performed with a nerve block, using local anesthetic without epinephrine. A successful nerve block that confirms the diagnosis must reduce the pain level by at least 5 visual analog scale (VAS) level points. If there is residual pain, then either there is a second nerve contributing to the pain mechanism, a second more proximal spot of injury on the same nerve, a central mechanism for the pain, or the patient is malingering.

If the diagnosis is a neuroma of, for example, the supraorbital branch of the trigeminal nerve, and the patient desires surgical treatment, then there are two options. First, one could resect the neuroma and reconstruct with a bioabsorbable neural conduit to restore sensation to an area of critical sensibility. Second, one could resect the neuroma and leave the area without normal sensibility. A neurolysis of the nerve can be attempted, but if there is true intraneural damage, the pain will remain and may even become worse after the neurolysis. Therefore, while neurolysis of this nerve has been reported,${ }^{19}$ the craniomaxillofacial surgeon must be prepared to resect the painful nerve.

If the neuroma is resected, the question becomes where to relocate the proximal end of the trigeminal nerve. For the extremities this problem has been resolved: implantation of the proximal end of a sensory nerve into intact, innervated muscle prevents formation of a classic neuroma. ${ }^{20}$ Strategies for implantation of a sensory nerve in the upper or lower extremity have been reported with long-lasting, predictable relief of pain by implanting the proximal end of the nerve, after neuroma resection, into adjacent innervated muscles. ${ }^{21-24}$ The problem in the maxillofacial region is that the facial muscles do not have sufficient bulk to apply this strategy. 
Table 2 Conceptual Solutions for Location of Proximal Trigeminal Nerve after Neuroma Resection

\begin{tabular}{ll}
\hline Trigeminal Nerve Branch & "Implantation Site" \\
\hline Supraorbital nerve & Orbit \\
Infratrochlear nerve & Orbit \\
$\begin{array}{l}\text { External nasal (branch of } \\
\text { anterior ethmoidal) }\end{array}$ & Orbit \\
Zygomatico-temporal & Orbit \\
Zygomatico-facial & Orbit \\
Infraorbital nerve & Orbit or maxillary sinus \\
Inferior alveolar nerve & Pterygoid muscle or \\
& reconstruct to mental nerve \\
\hline
\end{tabular}

Table 2 contains the hypothetical or conceptual solutions to this problem for branches of the trigeminal nerve. It will remain for future clinical studies to identify the most successful strategy for treatment of the painful trigeminal neuroma.

An additional consideration is the painful neuroma related to a sensory nerve with critical sensory function. For example, for painful neuromas in the hand after toe-to-thumb transfer, the most appropriate treatment of the painful neuroma is to resect the neuroma and then reconstruct the nerve, as sensibility of the thumb is of critical importance. ${ }^{25}$ In the maxillofacial region, this concept could be applied to the jaw, in which jaw pain after excision of an impacted third molar results in chronic pain. The best approach in this situation is to reconstruct the inferior alveolar nerve and restore sensibility to the lower lip. ${ }^{16,26}$

\section{Compression}

Carpal tunnel syndrome is the most common and most well-understood chronic nerve compression. The words used to describe chronic nerve compression are "numbness and tingling" (paresthesias) and not pain. Yet, for some individuals, chronic nerve compression can be perceived as chronic pain. This is most often seen in the setting of a peripheral nerve neuropathy. However, in the face, persistent tingling and numbness can become sufficiently distracting as to be disabling, and for some patients the perception is one of pain. In a partially injured nerve, there can be components of both true nerve injury, with axonal sprouting causing pain, as well as chronic compression.

The most common sources of chronic nerve compression in the maxillofacial region are related to cosmetic surgery and facial trauma. The endoscopic brow approaches lend themselves to putting excess tension on the supraorbital and infratrochlear nerves. The subperiosteal midface lift and newer tacking techniques using absorbable ribbons or nonabsorbable sutures lend themselves to putting excess tension on the infraorbital nerve (Fig. 2), and perhaps creating true neuromas of the zygomatico-temporal and zygomatico-facial nerves. With regard to facial fractures, either the trauma itself can compress the trigeminal nerve or its branches against the underlying bone or, as with the classic zygoma fracture, injure the nerve within the fracture site. ${ }^{27}$ Careful follow-up studies show that 6 months after a zygoma fracture, up to $50 \%$ of the patients may still have symptoms related to the infraorbital nerve.

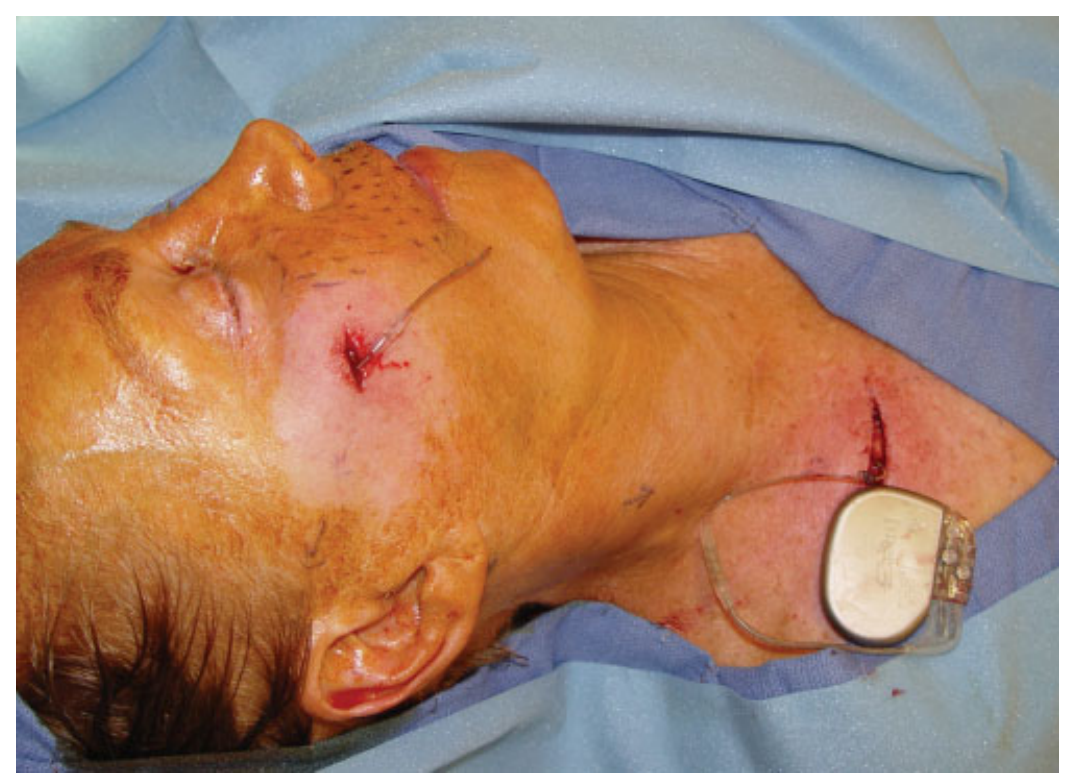

Figure 2 Chronic midfacial pain after a subperiosteal secondary face lift 3 years prior to presentation. The area of the patient's pain is noted by the blue dots on her right cheek, extending to the side of the nose and the upper lip. An implanted peripheral nerve stimulator was placed along her infraorbital nerve 2 years into her chronic pain condition after all neuropathic pain medication failed to help relieve her pain. The stimulator is being removed in this view. Note the battery pack on her chest where it had been located subcutaneously. (From Dellon AL. Pain Solutions. (C) 2007, used with permission.) 


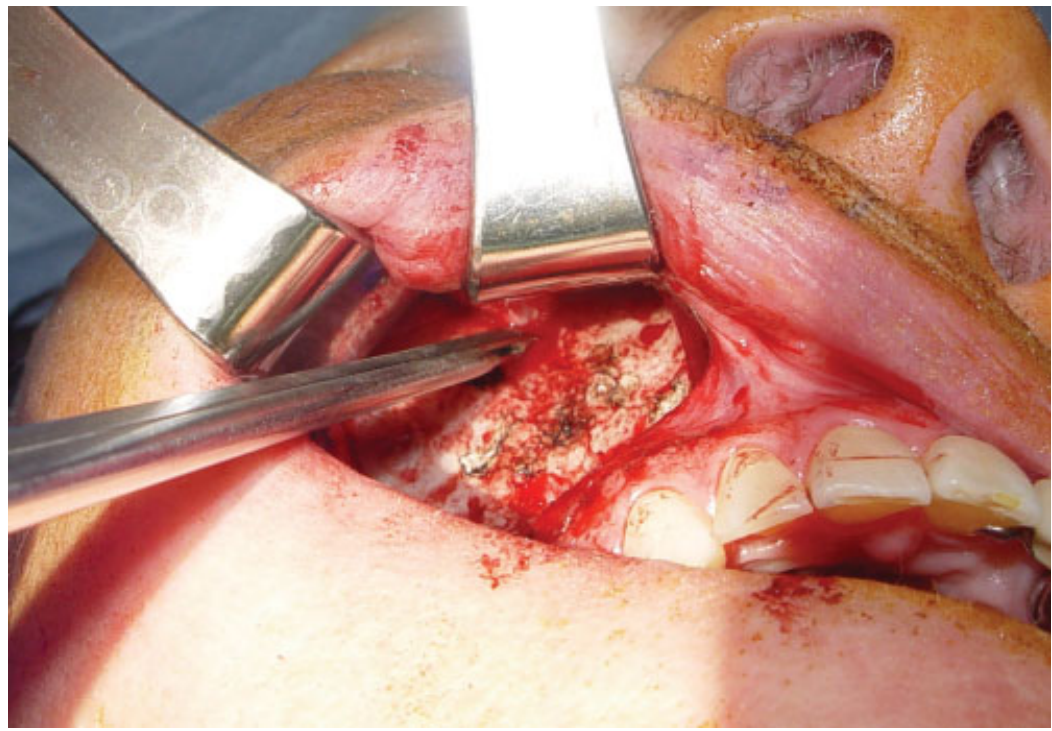

Figure 3 Same patient as in Fig. 2. Here, through a superior labial sulcus incision, the infraorbital nerve was identified. The nerve was adherent to the surrounding bone. A neurolysis was performed with good relief of her pain and preservation of her sensation. (From Dellon AL. Pain Solutions. (C) 2007, used with permission.)

True compression of a peripheral nerve should be treated by neurolysis. ${ }^{11}$ Neurolysis for the supraorbital nerve has been described and is conceptually simple. Neurolysis of the infraorbital nerve has not been described. In our experience with one patient, a superior labial sulcus incision was used to approach the infraorbital nerve, and this did permit a neurolysis (Fig. 3). This patient's compression was from the midface lift component of a secondary rhytidectomy. For some patients in whom the compression of the infraorbital nerve is related to malar reconstruction with implants or a bone graft, decompression may require removal of the implant (Fig. 4). In patients with pain persisting after a zygoma fracture, it may be necessary to re-create the fracture with an osteotomy, and then reset the zygoma after neurolysis of the infraorbital nerve. In patients with an orbital floor fracture, a neurolysis of the infraorbital nerve within the orbit will be necessary, most likely with an orbital floor reconstruction (Fig. 5).

(The concept that migraine headaches can be due to compression of branches of the trigeminal nerve will be discussed in the section "Migraine Headaches and the Trigeminal Nerve.")

\section{EVALUATION OF FACIAL SENSIBILITY}

It is necessary to arrive at a correct diagnosis before deciding upon a treatment plan. With the exception of the VAS to record the patient's pain level, ${ }^{28,29}$ there is no device available to measure pain thresholds in the face. However, the same nerve that contains the unmyelinated and small myelinated pain fibers also contains the large myelinated touch fibers. The cutaneous pressure threshold of the quickly and slowly adapting fiber/receptor systems can be measured with the Pressure-Specified Sensory Device (PSSD; Sensory Management Services, LLC, Baltimore, MD). The PSSD has been well documented for evaluation of sensibility in the upper ${ }^{30,31}$ and lower ${ }^{32}$ extremities and recently has been used to document the sensory outcomes of breast augmentation ${ }^{33}$ and reduction. ${ }^{34}$ Recently, the normative data for the

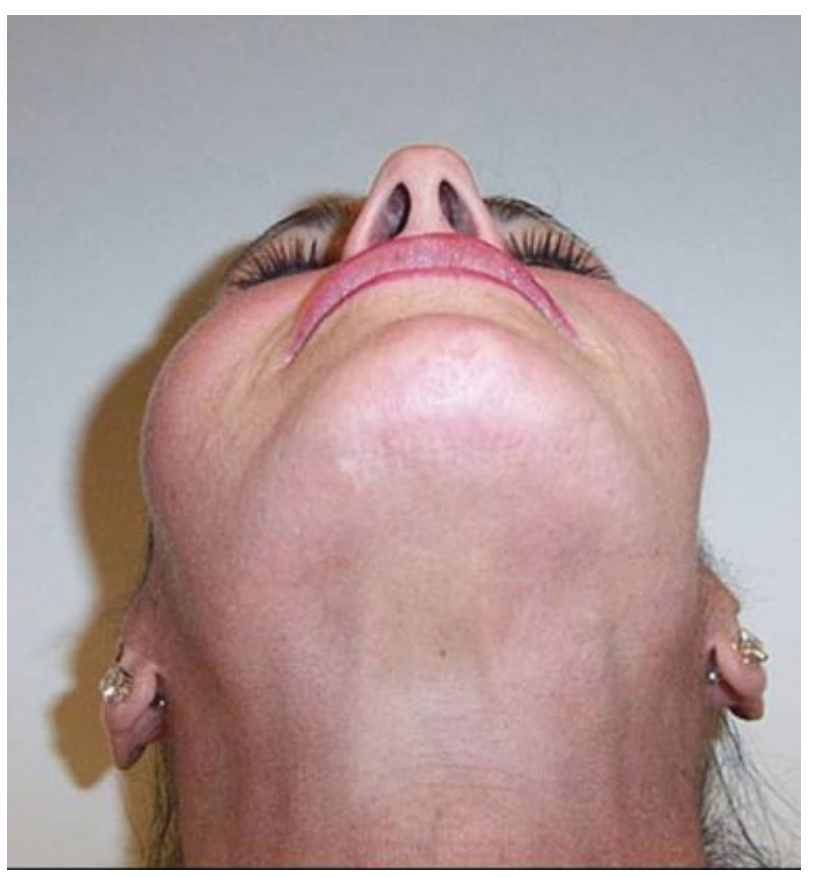

Figure 4 This patient has had four separate malar augmentations by other surgeons. After the last malar augmentation, the implant on the right side became infected and shifted position. She developed chronic right cheek and lip pain. This required repositioning of the implant. 


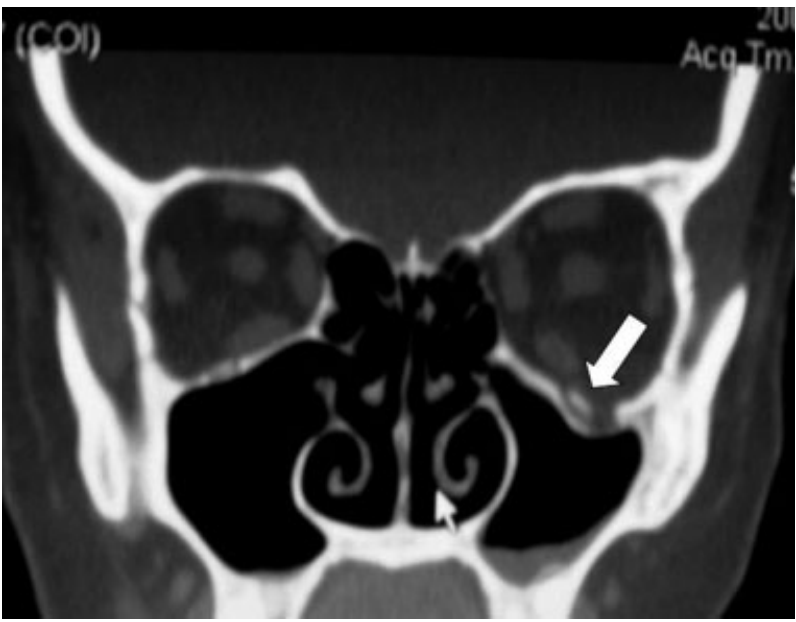

Figure 5 A CT scan of right orbital floor in a woman who had fallen 7 months previously. She had nonsurgical management of her orbital floor fracture but was referred for persistent aching in her cheek and numbness extending to her lip and side of her nose. A large white arrow demonstrates a small bone fragment that can be seen in the infraorbital canal. The small white arrow is an artifact of the original CT scan image. A neurolysis of the infraorbital nerve through a subconjunctival approach, removal of the roof of the canal, and reconstruction of the orbital floor with a nonadherent alloplastic material would be an appropriate treatment.

trigeminal nerve skin territories has been published, ${ }^{35}$ with these territories chosen as those sites most likely to be involved with chronic pain due to nerve injury or compression. Whereas facial sensibility has been eval- uated in the past with vibrometry, classic 2-point discrimination, and with the Semmes-Weinstein monofilaments, ${ }^{36-44}$ each of these devices has significant drawbacks in measuring sensibility. ${ }^{45}$

To test facial sensibility, the patient is seated comfortably, with a response button in his or her hand. The tester places the PSSD against the desired skin surface to be tested and can test either 1-point movingor static-touch, or 2-point moving- or static-touch (Fig. 6). Examples of the test report are given in Fig. 7A,B for a nerve regeneration pattern and for a severely damaged infraorbital nerve from the patients in Figs. 2 and 4.

The PSSD evaluation (1) documents that there is a problem with a branch or branches of the trigeminal nerve, (2) demonstrates whether the nerve is regenerating or degenerating, and (3) demonstrates the degree of axonal loss. Based on these measurements, a plan for treatment of the trigeminal nerve can be determined. For example, if there is a regenerating pattern in the patient after a malar implant, a dental implant, or orthognathic surgery (see next section), then no surgery may be indicated. However, if there is loss of axonal function, then either the implant has to be removed or repositioned or the neuroma needs to be resected and/or the nerve reconstructed.

\section{ORTHOGNATHIC SURGERY}

It is possible that $100 \%$ of patients having a mandibular osteotomy of one kind or another will have transient

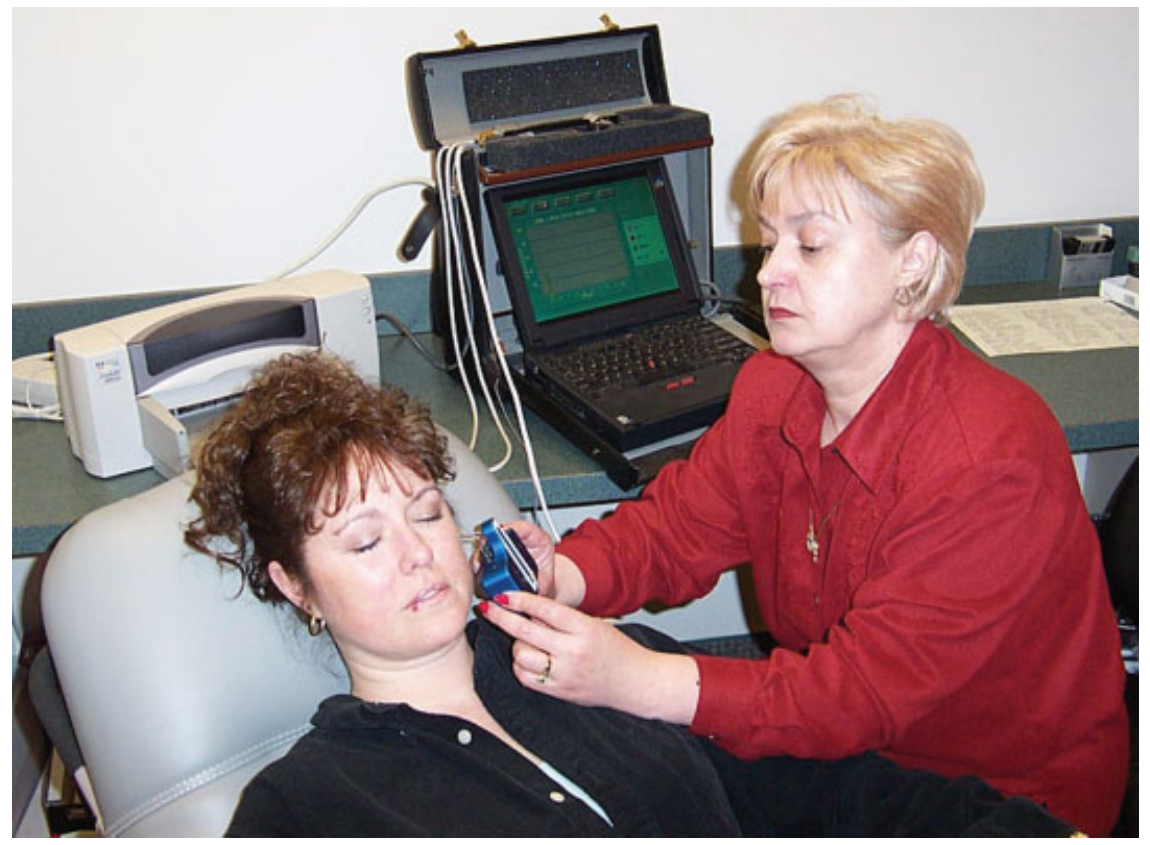

Figure 6 Neurosensory testing setup with the Pressure-Specified Sensory Device. The patient is seated comfortably in a recliner. The examiner applies the PSSD to the desired skin surface with increasing pressure. When the patient perceives the stimulus, the hand-held button is pushed and the PSSD stops acquiring information. (From Dellon AL. Pain Solutions. (C) 2007, used with permission.) 

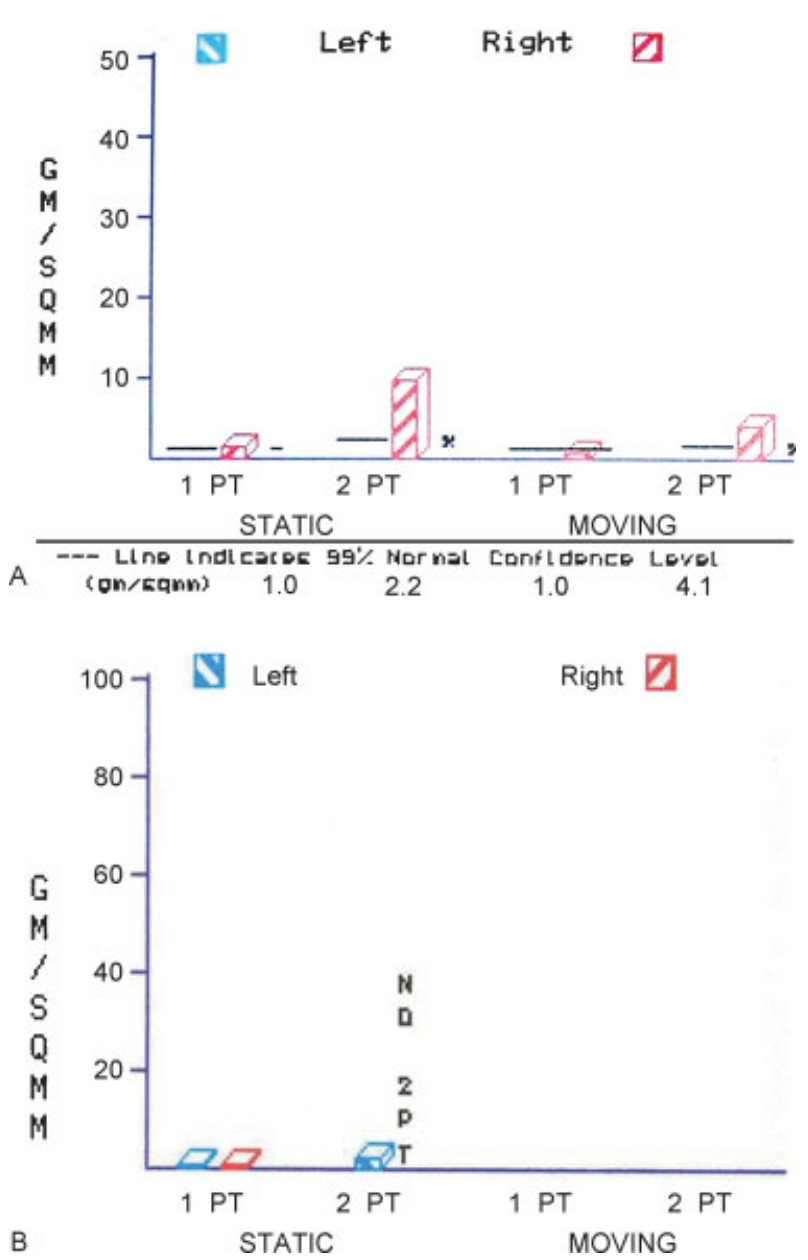

Figure 7 The cutaneous pressure threshold obtained with the PSSD can identify whether the nerve supplying the given piece of skin is undergoing neural regeneration or chronic nerve compression. The right side appears in red and the left side in blue. The $y$-axis measures the pressure threshold in $\mathrm{gm} / \mathrm{mm}^{2}$. The $x$-axis lists the type of touch stimuli delivered to the skin. For a nerve regeneration pattern, 1-point moving recovers first (lowest pressure recorded for 1PM), then 1point static recovers (1PS), and then as more nerve fibers regenerate, 2-point moving touch (2PM) and finally 2-point static (2PS) recovers. There is an asterisk $\left({ }^{*}\right)$ near the $2 \mathrm{PM}$ and 2PS indicating that the distance at which one from two can be distinguished is present but not normal. (A) This pattern is seen for the right cheek in the patient in Fig. 2 who had a neurolysis of the right infraorbital nerve. (B) An example of severe sensory loss as was seen in the patient in Fig. 4 who had surgery to decompress the nerve. Note there is no bar present at all for the right infraorbital nerve measured over the cheek. This pattern is also consistent with the presence of a nerve division or a neuroma being present, and urgent surgery is indicated.

sensory loss, paresthesias, or pain. For example, Posnick et al reported the following percentage of subjective residual symptoms at 1 year in $28 \%$ of patients having a sagittal split, in $10 \%$ of patients having an osteoplastic genioplasty, and in $67 \%$ of patients having a combined sagittal split and an osteoplastic genioplasty. ${ }^{42}$ Measurement of classic 2-point discrimination only demonstrated a statistically significant difference between those patient having the combined procedure and the normal control group in the sensibility of the chin. ${ }^{42}$ These nerve injuries could include the entire range from nerve division to stretch/traction injury, with the combined group being at the most risk because the nerve was exposed/involved at two different sites along its axis (double crush concept).

The incidence of direct nerve injury (division) noted by the surgeon at the time of surgery during sagittal split has been reported to be $2.1 \%$ (27 in a consecutive series of 1264 patients). ${ }^{46}$ This is an important area in which contributions remain to be made. If a nerve is injured intraoperatively and that injury is observed, then the ability to resect the edges damaged by the saw and reconstruct immediately with a neural conduit without having to do a nerve graft should be considered. In the postoperative period, monitoring trigeminal nerve function in the lower lip and chin in these high-risk patients would seem to offer documentation and reassurance that the pain is due to neural regeneration, if it is occurring, or provide the basis for nerve division/reconstruction if the pain persists.

\section{TEMPOROMANDIBULAR JOINT PAIN}

Chronic facial pain can be related to the temporomandibular joint (TMJ). This can occur related to dentition problems as well as intrinsic TMJ abnormalities. In the patient who has persistent TMJ pain despite all possible dental attempts to correct malocclusion, and in the patient who has persistent TMJ pain despite attempts to reconstruct the joint itself, then the concept that the pain is being transmitted by the nerves that innervate that joint must be considered. The innervation of the TMJ has been described. ${ }^{47}$ The auriculotemporal branch of the mandibular branch of the trigeminal nerve innervates the lateral aspect of the TMJ while the masseteric motor branch of $\mathrm{V}_{3}$ sends a small branch to innervate the medial aspect of the TMJ. These nerves most likely are involved in neuroma formation within the capsular scar after the previous surgical procedures. These branches can be blocked, and if the TMJ pain is relieved, then pain relief can be obtained theoretically by a denervation of the TMJ. One such case has been reported. $^{48}$

\section{CERVICAL PLEXUS AS SOURCE OF FACIAL PAIN}

Chronic facial pain can be due to involvement of the cervical plexus. The $\mathrm{C} 2$ and $\mathrm{C} 3$ nerves have dermatomes that cover the occiput, the neck, and the lateral jaw 


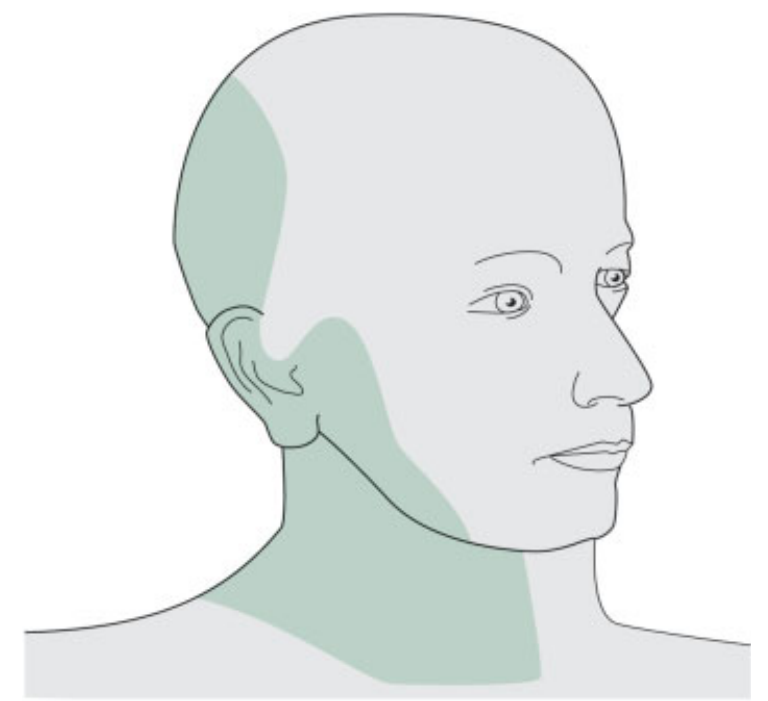

Figure 8 The dermatomal distribution of $\mathrm{C} 2$ and $\mathrm{C} 3$ (Adapted from Foester O. The dermatomes in man [Schorstein Lecture, London, 1932]. Brain 1933;56:I-39.)

(Fig. 8). Chronic pain in and about the earlobe is a classic complication of damaging the greater auricular nerve during a rhytidectomy. Following the paradigm for the treatment of the painful neuroma in the extremity, the senior author has treated this problem successfully by identifying the nerve in the posterior cervical triangle as it exits the sternocleidomastoid muscle, interrupting its nerve function at this point (not necessary to reopen the rhytidectomy incision), and implanting the nerve into the deep surface of the sternocleidomastoid muscle.

In patients with brachial plexus compression in the thoracic inlet (so-called thoracic outlet syndrome), symptoms often include posterior headaches and lateral facial pain. Often the patients have had evaluations for TMJ problems. The senior author's approach, using a supraclavicular approach and resecting the anterior scalene muscle (leaving the first rib), ${ }^{49}$ has been effective in relieving these headaches and lateral facial pain. The cervical plexus travels deep to the anterior scalene muscle before it surfaces at the posterior border of the sternocleidomastoid muscle. Our hypothesis is that the spasticity and tightness of the anterior scalene muscle causes compression of the cervical plexus and results in this chronic facial pain syndrome that accompanies "thoracic outlet syndrome." Therefore, evaluation of the cervical plexus and the brachial plexus should become part of the evaluation of chronic lateral facial pain and posterior headaches.

\section{MIGRAINE HEADACHES AND THE TRIGEMINAL NERVE}

In 2000, Guyuron et al published his observation that, in patients with a history of migraine headaches having forehead rejuvenation surgery, there was a decrease or disappearance of their migraine headaches in the postoperative period ${ }^{50}$ In that surgery, the corrugator supercilii was resected. Guyuron went on to introduce botulinium toxin type A (Botox; Allergan, Inc., Irvine, $\mathrm{CA}$ ) injections into the muscle prior to surgery as a diagnostic test to determine if the migraine headaches would be affected by reduction in muscle function. ${ }^{51} \mathrm{It}$ was clear that the supraorbital nerve could be compressed by this muscle. Guyuron extended this concept that compression of certain nerves was in part responsible for frontal and occipital forms of migraine headaches and continued to document his results and extend his observations to anatomic dissections of the greater, lesser, and third occipital nerves and the corrugator muscles themselves. ${ }^{52-54}$ In 2006, he held his first workshop on this subject, and his second workshop was held in 2007. As his approach is studied and accepted by others, decompression of these nerves will become part of our approach to chronic facial pain related to headaches. It remains to be determined whether all of these nerves should be decompressed or whether some should be resected. It remains to be determined whether the diagnosis of these nerve compressions can be identified with PSSD testing.

It remains to be determined what are the mechanisms related to the chronic pain and the nerve compressions. The senior author would like to suggest the mechanism of this referred pain. It is accepted that myocardial infarction can give symptoms of jaw pain or arm pain, and this is attributed to a spinal cord referred pain. Theoretically, embryologically, the heart begins in the lower pharyngeal and brachial arches, which also give off nerves to the side of the face and the arm. It is also known that carcinoma arising in the pyriform sinus in the larynx can present as ear pain, due to the innervation of the mucosa of the pyriform sinus from branches of the vagus nerve. The vagus nerve also innervates, via the nerve of Arnold, a small portion of the external ear and eustachian tube-again, a referred pain pathway. It has been observed that visceral complaints related to the pelvic organs can be due to injury to the iliohypogastric nerve. ${ }^{55}$ Hypothetically, this can be due to the sympathetic and parasympathetic innervation of the pelvic organs arising from the same L1 and L2 level in the spinal cord as the iliohypogastric nerves. Again, a plausible referred pain pathway exists. It is possible that the innervation of the meninges by branches of the trigeminal nerve before it exists the cranium may be the source of the referred pain for headaches that is initiated by compression of the supraorbital nerves extracranially.

\section{CONCLUSION}

Chronic facial pain deleteriously changes the lives and function of patients who suffer from its causes. Its 
etiology may be challenging to diagnose and difficult or frustrating to treat. There is still much to be learned and refined about its mechanisms and treatment. However, some successful surgical strategies for trigeminal nerve pathologies have been discussed. Nerve reconstruction will continue to be explored. The etiologies of chronic nerve compressions and treatment strategies may elucidate simple solutions to debilitating problems. The measurement of facial sensibility may give us significant diagnostic and prognostic information, which will drive our treatment strategies.

\section{CONFLICT OF INTEREST}

A. Lee Dellon, M.D., has a conflict of interest in that he owns Sensory Management Services, LLC, which sells and distributes the Pressure-Specified Sensory Device ${ }^{\mathrm{TM}}$, a device which he invented. Measurements made with this device are used in this study. The terms of this arrangement are being managed by the Johns Hopkins University in accordance with its conflict of interest policies.

Devices used in the study described in this article were provided by Synovis Microsystems. Dr. Dellon is entitled to a share of royalty received on sales of products described in this article. The terms of this arrangement are being managed by the Johns Hopkins University in accordance with its conflict of interest policies.

\section{REFERENCES}

1. Sternbach RA. Acute versus chronic pain. In: Wall PD, Melzack R, eds. Textbook of Pain. New York, NY: Churchill Livingstone; 1984:173-177

2. Wall PD. Introduction. In: Wall PD, Melzack R, eds. Textbook of Pain. New York, NY: Churchill Livingstone; 1984:1-16

3. Livingston WK. Pain Mechanisms. New York, NY: MacMillan; 1942;69

4. Bonica JJ. The Management of Pain. Philadelphia, PA: Lea and Febinger; 1953:154-156

5. Waldman S. Atlas of Common Pain Syndromes. Philadelphia, PA: WB Saunders; 2002

6. Jannetta PJ. Arterial compression of the trigeminal nerve at the pons in patients with trigeminal neuralgia. J Neurosurg 1967;26:159-162

7. Shelton ML. Working in a Very Small Space: The Making of a Neurosurgeon. New York, NY: WW Norton; 1989

8. Jannetta PJ. Neurovascular compression in cranial nerve and systemic disease. Ann Surg 1980;192:518-525

9. Sindou M, Leston J, Decullier E, et al. Microvascular decompression for primary trigeminal neuralgia: long-term effectiveness and prognostic factors in a series of 362 consecutive patients with clear cut neurovascular conflicts who underwent pure decompression. J Neurosurg 2007;107: 1144-1153
10. Baker FG, Jannetta PJ, Bissonette DJ, et al. The long-term outcome of microvascular decompression for trigeminal neuralgia. N Engl J Med 1996;334:1077-1083

11. Mackinnon SE, Dellon AL. Surgery of the Peripheral Nerve. New York, NY: Thieme Medical Publishers; 1989

12. Dellon AL, Aszmann OC, Muse V. Collateral sprouting documentation using the PSSD. Ann Plast Surg 1996;37: 520-525

13. Dellon AL. Resection: nerve repair's most neglected technique. Plast Surg Techn 1995;1:191-199

14. Zachary LS, Dellon AL, Seiler WA IV. Relationship of intraneural damage in the rat sciatic nerve to the mechanism of injury. J Reconstr Microsurg 1989;5:137-140

15. Weber RA, Briedenbach WC, Brown RE, et al. A randomized prospective of polyglycolic acid conduits for digital nerve reconstruction in humans. Plast Reconstr Surg 2000;106:1036-1045

16. Crawley WA, Dellon AL. Inferior alveolar nerve reconstruction with a polyglycolic acid, bioabsorbable nerve conduit: a case report. Plast Reconstr Surg 1992;90:300-302

17. Ducic I, Maloney CT, Dellon AL. Reconstruction of the spinal accessory nerve: autograft or neurotube? Two case reports J Reconstr Microsurg 2005;21:29-33

18. Navissano M, Malan F, Carnino R, et al. Neurotube for facial nerve repair. Microsurgery 2005;25:268-271

19. Ramirez OM, Pozner JN. Endoscopically assisted supraorbital nerve neurolysis and correction of eyebrow asymmetry. Plast Reconstr Surg 1997;100:755-758

20. Mackinnon SE, Dellon AL, Hudson AR, et al. Alteration of neuroma formation by manipulation of neural microenvironment. Plast Reconstr Surg 1985;76:345-352

21. Dellon AL, Aszmann OC. Treatment of dorsal foot neuromas by translocation of nerves into anterolateral compartment. Foot Ankle 1998;19:300-303

22. Dellon AL, Mackinnon S. Treatment of the painful neuroma by neuroma resection and muscle implantation. Plast Reconstr Surg 1986;77:427-436

23. Evans GRD, Dellon AL. Implantation of the palmar cutaneous branch of the median nerve into the pronator quadratus for treatment of painful neuroma. J Hand Surg [Am] 1994;19:203-206

24. Mackinnon SE, Dellon AL. Results of treatment of recurrent dorsoradial wrist neuromas. Ann Plast Surg 1987;19:54-61

25. Dellon AL, Maloney CT Jr. Salvage of sensation in a halluxto-thumb transfer by nerve tube reconstruction. J Hand Surg [Am] 2006;31:1495-1498

26. Evans GRD, Crawley W, Dellon AL. Inferior alveolar nerve grafting: an approach without intermaxillary fixation. Ann Plast Surg 1994;33:221-224

27. Fogaça WC, Fereirra MC, Dellon AL. Neurosensory testing in evaluation of infraorbital nerve injuries associated with zygoma fracture. Plast Reconstr Surg 2004;113:834-838

28. Price DD, McGrath PA, Rafii A, Buckingham B. The validation of visual analogue scales as ratio scale measures for chronic and experimental pain. Pain 1983;17:45-56

29. Revill SI, Robinson JO, Rosen M, Hogg MI. The reliability of a linear analogue for evaluating pain. Anaesthesia 1976;31: 1191-1198

30. Dellon AL, Keller KM. Computer-assisted quantitative sensory testing in carpal and cubital tunnel syndromes. Ann Plast Surg 1997;38:493-502 
31. Rosenberg D, Conolley J, Dellon AL. Thenar eminence quantitative sensory testing in diagnosis of proximal median nerve compression. J Hand Ther 2001;14:258-265

32. Tassler PL, Dellon AL. Pressure perception in the normal lower extremity and in tarsal tunnel syndrome. Muscle Nerve 1996;19:285-289

33. Okwueze MI, Spear ME, Zwyghuizen AM, et al. Effect of augmentation mammaplasty on breast sensation. Plast Reconstr Surg 2006;117:73-83

34. Mofid MM, Klatsky SA, Singh NK, et al. Nipple-areola complex sensitivity after primary breast augmentation: a comparison of periareolar and inframammary incision approaches. Plast Reconstr Surg 2006;117:1694-1698

35. Dellon AL, Andonian E, DeJesus RA. Measuring sensibility of the trigeminal nerve. Plast Reconstr Surg 2007;120:15461550

36. Costas PD, Heatley G, Seckel BR. Normal sensation of the human face and neck. Plast Reconstr Surg 1994;93:11411145

37. Kesarwani A, Antonyshyn O, Mackinnon SE, et al. Facial sensibility testing in the normal and posttraumatic population. Ann Plast Surg 1989;22:416-425

38. Lawrence JE, Poole MD. Mid-facial sensation following craniofacial surgery. Br J Plast Surg 1992;45:519-522

39. Novak CB, Ross B, Mackinnon SE, Nedzelski JM. Facial sensibility in patients with unilateral facial nerve paresis. Otolaryngol Head Neck Surg 1993;109:506-513

40. Posnick JC, Al-Qattan MM, Pron G. Facial sensibility in adolescents with and without clefts one year after undergoing Le Fort I osteotomy. Plast Reconstr Surg 1994;94:431-435

41. Posnick JC, Al-Qattan MM, Pron GE, et al. Facial sensibility in adolescents born with cleft lip after undergoing repair in infancy. Plast Reconstr Surg 1994;93:682-685

42. Posnick JC, Al-Qattan MM, Stepner NM. Alteration in facial sensibility in adolescents following sagittal split and chin osteotomies of the mandible. Plast Reconstr Surg 1996; 97:920-927
43. Posnick JC, Zimbler AG, Grossman JA. Normal cutaneous sensibility of the face. Plast Reconstr Surg 1990;86:429-433

44. Rosenberg A, Sailer HF. A prospective study on changes in the sensibility of the oral mucosa and the mucosa of the upper lip after Le Fort I osteotomy. J Craniomaxillofac Surg 1994;22: 286-293

45. Dellon AL. Somatosensory Testing and Rehabilitation. Bethesda, MD: American Occupational Therapy Association; 1997

46. Teltzrow T, Kramer FJ, Schulze A, et al. Perioperative complications following sagittal split osteotomy of the mandible. J Craniomaxillofac Surg 2005;33:307-313

47. Davidson JA, Metzinger SE, Tufaro AP, Dellon AL. Innervation of the temporomandibular joint. J Craniofac Surg 2003;14:235-239

48. Dellon AL, Maloney CT Jr. Denervation of the painful temporomandibular joint. J Craniofac Surg 2006;17:828-832

49. Dellon AL. "Brachial plexus compression" (not "thoracic outlet syndrome"): treatment by supraclavicular plexus neurolysis. J Reconstr Microsurg 1993;9:11-18

50. Guyuron B, Varghai A, Michelow BJ, et al. Corrugator supercili muscle resection and migraine headaches. Plast Reconstr Surg 2000;106:429-434

51. Guyuron B, Tucker T, Kriegler J. Botulinium toxin A and migraine surgery. Plast Reconstr Surg 2003;112:171S-173S

52. Dash KS, Janis JE, Guyuron B. The lesser and third occipital nerves and migraine headaches. Plast Reconstr Surg 2005;115: 1752-1758

53. Guyuron B, Kriegler JS, Davis J, et al. Comprehensive surgical treatment of migraine headaches. Plast Reconstr Surg 2005;115:1-9

54. Janis JE, Ghavami A, Lemmon JA, et al. Anatomy of the corrugator supercilii muscle. Part I: corrugator topography. Plast Reconstr Surg 2007;120:1647-1652

55. Liszka TG, Dellon AL, Manson PN. Iliohypogastric nerve entrapment following abdominoplasty. Plast Reconstr Surg 1994;93:181-184 